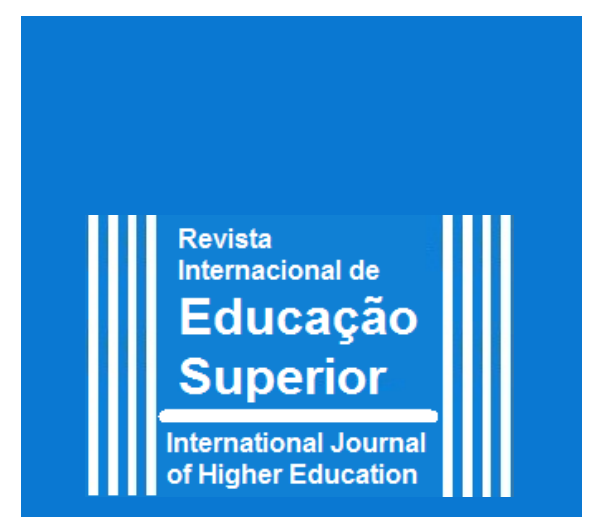

\section{Política Externa Brasileira, Cooperação Sul-Sul e Ensino Superior Brasileiro}

\author{
Marília Ribas Machado ${ }^{1}$ (iD) http://orcid.org/0000-0002-4684-8627 \\ Mario Cesar Barreto Moraes² (D) http://orcid.org/0000-0002-0760-8444 \\ 1,2 Universidade do Estado de Santa Catarina
}

\section{RESUMO}

Este artigo tem o objetivo de verificar em que medida o Programa Estudantes Convênio de Pós-Graduação (PEC-PG) pode ser considerado como um programa que atende aos princípios da Cooperação Sul-Sul (CSS). Para tanto, buscou-se investigar mais a fundo qual o posicionamento da política externa brasileira no momento de concepção do programa, depois buscou-se compreender os motivos reais que proporcionaram a criação do PEC-PG e por fim, buscou-se investigar a concepção de Cooperação Sul-Sul e observar em que medida ela se distancia do modelo comum de cooperação e descobrir se o Programa Estudantes Convênio de Pós-Graduação (PEC-PG) poderia ser considerado um programa de cooperação que atende aos princípios que balizam a Cooperação Sul-Sul. O desenvolvimento do trabalho se deu através de buscas documentais, periódicos, teses e livros, o paradigma adotado foi o interpretativista, uma vez que o sujeito vê o mundo social na forma de um processo social criado pelos indivíduos envolvidos. Como considerações finais, foi possível observar que o PEC-PG foi criado ensejando auxiliar o desenvolvimento econômico nacional da época e que, embora seja um programa de cooperação entre os países do Sul, não pode ser caracterizado como um programa que atende aos princípios da Cooperação Sul-Sul, pois algumas prerrogativas do programa se distanciam do proposto pela CSS.

\section{PALAVRAS-CHAVE}

Educação superior. Cooperação sul-sul. Política externa brasileira.
Florianópolis, Santa Catarina, Brasil

\section{Lattes}

http://lattes.cnpq.br/5229585117502398

\section{Submetido: 21 abr. 2020 \\ Aceito: 07 dez. 2020}

Publicado: 31 mar. 2021

doi? 10.20396/riesup.v7i0.8659233 e-location: e021042

ISSN 2446-9424

Checagem Antiplagiarismo

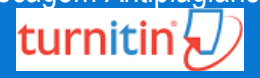

Distribuído sobre

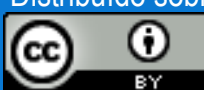

EY 


\section{Brazilian Foreign Policy, South-South Cooperation and Brazilian Higher Education}

\section{ABSTRACT}

This article aims to verify to what extent the Students-Graduate Agreement Program can be considered as a program that meets the principles of South-South Cooperation. To this end, we sought to further investigate the positioning of Brazilian foreign policy at the time the program was conceived, then we sought to understand the real reasons that led to the creation of the PEC-PG and, finally, we sought to investigate the conception SouthSouth Cooperation Program and observe the extent to which it distances itself from the common cooperation model and find out if the Graduation Agreement Students Program - PEC-PG could be considered a cooperation program that meets the principles that guide South-South cooperation. The development of the work took place through documentary searches, periodicals, theses and books, the paradigm adopted was the interpretative one, since the subject sees the social world in the form of a social process created by the individuals involved. As final considerations, it was possible to observe that the PEC-PG was created with the intention of helping the national economic development of the time and that, although it is a cooperation program between the countries of the South, it cannot be characterized as a program that meets the principles of cooperation South-South, as some of the program's prerogatives differ from the one proposed by the CSS.

\section{KEYWORDS}

Higher education. South-south cooperation. Brazilian foreign

\section{Política Exterior Brasileña, Cooperación Sur-Sur y Educación Superior Brasileño}

\section{RESUMEN}

Este artículo tiene como objetivo verificar en qué medida el Programa de Acuerdo de Estudiantes y Graduados puede considerarse como un programa que cumple con los principios de Cooperación Sur-Sur. Con este fin, buscamos investigar más a fondo el posicionamiento de la política exterior brasileña en el momento en que se concibió el programa, luego buscamos comprender las razones reales que llevaron a la creación del PEC-PG y, finalmente, buscamos investigar la concepción Programa de Cooperación Sur-Sur y observe hasta qué punto se distancia del modelo de cooperación común y descubra si el Programa de Estudiantes del Acuerdo de Graduación - PEC-PG podría considerarse un programa de cooperación que cumple con los principios que guían la cooperación Sur-Sur. El desarrollo del trabajo se llevó a cabo a través de búsquedas documentales, publicaciones periódicas, tesis y libros, el paradigma adoptado fue el interpretativo, ya que el sujeto ve el mundo social en la forma de un proceso social creado por los individuos involucrados. Como consideraciones finales, fue posible observar que el PEC-PG fue creado con la intención de ayudar al desarrollo económico nacional de la época y que, aunque es un programa de cooperación entre los países del Sur, no puede caracterizarse como un programa que cumpla con los principios de cooperación Sur-Sur, ya que algunas de las prerrogativas del programa difieren de la propuesta por el CSS.

\section{PALABRAS CLAVE}

Educación superior. Cooperación sur-sur. Política exterior brasileña. 


\section{Introdução}

Historicamente, a política externa brasileira foi construída em torno de um empreendimento majoritário: o desenvolvimento do país por meio de autonomia e de um papel significativo no sistema internacional (LEAL; MORAES, 2018). Esse discurso desenvolvimentista tinha o propósito de unificar, dentro das possibilidades, forças políticas e socioeconômicas brasileiras em prol da superação do subdesenvolvimento nacional, da modernidade e da projeção internacional mais assertiva do país (MANZUR, 2014).

Principalmente após a década de 1970, o Brasil passou a orientar suas relações exteriores para o aperfeiçoamento dos laços com diversos países, contrariando inclusive uma perspectiva de afastamento e isolamento em relação à América Latina (BESHARA; PINHEIRO, 2008). Os governos brasileiros cotejavam fazer da política exterior um programa de ação global mantendo relações com todos os países, sem distinção de seus sistemas (CERVO, 2002). A política externa destinava-se a trazer de fora insumos em apoio aos esforços internos, quais sejam capital, ciência e tecnologia e mercados externos, visando transitar da substituição de importações à substituição de exportações.

A partir desse objetivo, buscou-se o fortalecimento da região Sul como eixo alternativo de poder em um mundo cada vez mais multipolar (MILANI; MUÑOZ; KLEIN, 2015). A integração do Brasil com os países do entorno representava uma forma de "legitimar sua posição de liderança na América do Sul, além de consolidar um espaço de atuação internacional independente das orientações dos Estados Unidos" (ONUKI, 2006, p. 307). Essa posição como elemento impulsionador de uma agenda de desenvolvimento, elevou o país a patamares mais importantes de poder e influência no cenário internacional e de Cooperação Sul-Sul (CSS) (CANDEAS, 2012).

Na contramão das ações de cooperação Norte-Sul, a Cooperação Sul-Sul surge com o objetivo de propiciar o diálogo político e a articulação entre países em desenvolvimento, (SOUZA, 2014; CERVO; BUENO, 2015). Contudo, deve-se atentar ao fato de que esta articulação não se restringe somente a entendimentos nas esferas comercial e econômica, mas também se exprime por meio de acordos centrados em questões culturais e educacionais (PINHEIRO; BESHARA, 2012).

Porém, convém explicar que, embora relações aconteçam entre países subdesenvolvidos há uma relação de dependência evidenciada na educação superior mundial contemporânea. E, por este motivo, o Brasil deve procurar não reproduzir práticas com vínculos imperialistas ou neocolonizadoras, de contínua dependência econômica, política, cultural ou educacional com os países os quais mantém acordos de cooperação (LEAL; MORAES, 2018). 
Assim, torna-se indispensável conhecer a realidade, mensurar seus resultados e repensar seus impactos também na perspectiva do outro que é beneficiário da cooperação prestada (LEAL; MORAES, 2018; MILANI, 2012). No sentido de buscar não reproduzir relações que se caracterizem pela produção coletiva e a troca de conhecimento para o desenvolvimento econômico-social de ambas as partes (MOROSINI, 2011).

A partir de tal contexto, o objetivo deste artigo é verificar em que medida o Programa Estudantes Convênio de Graduação PEC-PG pode ser considerado um programa que atende aos princípios da cooperação Sul-Sul.

\section{Desenvolvimento}

O desenvolvimento deste artigo justifica-se tanto do ponto de vista teórico quanto empírico. Relativamente ao tema, uma revisão de literatura permitiu visitar o estado do conhecimento sobre a cooperação horizontal Sul-Sul na educação superior e sua relação com a internacionalização acadêmica, bem como os documentos de criação sobre o Programa Estudantes-Convênio de Pós-Graduação PEC-PG.

A epistemologia utilizada para compreensão do fenômeno estudado neste artigo foi a fenomenológica, visto que de acordo com Schutz (1979), a fenomenologia defende que é necessária uma melhor compreensão dos fenômenos, uma vez que ao se deparar com algo já carregamos um entendimento sobre aquilo, o que afeta nosso entendimento. O autor também argumenta que a fenomenologia dá uma "importância especial ao que já foi vivido em contraponto ao que está sendo experimentado, pois o que aconteceu no passado já está terminado e delimitado", sendo possível desta forma seu entendimento (SCHUTZ, 1979, p.63)

Reforça-se o exposto, ao considerar a experiência vivenciada pelos pesquisadores junto a grupos de atores do PEC-PG, para compreender suas aflições e considerações a respeito do programa.

Em relação ao paradigma, o que mais se adequou neste trabalho foi o interpretativista, uma vez que tem interesse em entender o mundo como ele é sem deixar de entender a natureza fundamental do mundo social. É através deste paradigma que o sujeito vê o mundo social em forma de um processo social que emerge do que foi criado pelos indivíduos envolvidos (BURRELL; MORGAN, 1979). Convém ainda explicitar que o interpretativismo guarda, em si, um conjunto de métodos e práticas típicos da pesquisa qualitativa, citando, entre outras, a etnografia e a observação participante e entrevista (BORTONI-RICARDO, 2008; DENZIN; LINCOLN, 2006).

Sobre o aspecto do paradigma interpretativista, este artigo foi assim caracterizado devido ao fenômeno ter sido observado sob uma ótica menos romântica e idealizada, buscando compreender quais os reais motivos que levaram a criação deste Programa de Cooperação e compreender em que medida este programa propicia o real fortalecimento e desenvolvimento da educação superior dos países de seu entorno tal como preconiza as teorias de Cooperação Sul-Sul. 


\section{Fundamentação Teórica}

Neste capítulo serão apresentadas as bases teóricas da política externa brasileira, de modo a contextualizar o tempo e o espaço no qual o Programa a ser analisado está inserido. Também serão abordados os tópicos de cooperação educacional e Cooperação Sul-Sul, pois estes tópicos fornecerão subsídios para melhor compreensão do artigo tendo em vista seu objetivo principal.

\section{Política Externa Brasileira}

Durante muito tempo o paradigma Americanista, pautado na busca de um alinhamento com os Estados Unidos como forma de elevar os recursos de poder no sistema internacional, fundamentou a política externa brasileira (PINHEIRO, 2004). A partir do início da Guerra Fria, a polarização ideológica entre comunismo e capitalismo estendia-se pelo mundo e ao conflito Leste-Oeste somava-se o conflito Norte-Sul que era caracterizado como um conflito não mais ideológico, mas que representava a variável do subdesenvolvimento econômico e suas consequências de pobreza e atrasos tecnológico e industrial (SOUZA, 2014; PINHEIRO, 2004).

Em alternativa ao Americanismo nasceu o Globalismo ou o Multilateralismo, cuja base de proposição se assentava em uma visão realista das relações internacionais principalmente apoiada no movimento latino-americano. Tal fenômeno apresenta uma representação constituída em quatro componentes: a) introduzir a diplomacia econômica nas negociações externas; b) promover a indústria por modo a satisfazer às demandas da sociedade; c) transitar da subserviência à autonomia com o fim de ganhos recíprocos nas relações internacionais; d) implementar um projeto nacional de desenvolvimento tendo em vista superar desigualdades entre nações (CERVO, 2003; PINHEIRO, 2004).

Essa postura desenvolvia-se, no Brasil, com vistas a articular os interesses econômicos e geopolíticos das organizações multilaterais, o desenvolvimento das comunicações e o transporte com o continente sul-americano, ensejando uma integração futura. O período dessas mudanças foi marcado pelo fim do confronto bipolar, pela ascensão do neoliberalismo e pela 'ascensão do resto', onde estão emergindo novos atores que em conjunto conseguem se contrapor aos Estados Unidos e barganhar seus interesses no âmbito Internacional (ZAKARIA, 2008).

A política brasileira para a América Latina, entre 1967 e 1979 foi conduzida por iniciativas de integração multilateral e o escalonamento da América Latina na estratégia de inserção mundial (CERVO; BUENO, 2015). Ainda de acordo com os autores Cervo e Bueno (2015, p.449), “a diplomacia brasileira esforçou-se por destruir estereótipos em voga no continente, que identificavam o Brasil ora como uma nova potência hegemônica, ora como executor de uma missão subimperial a serviço dos Estados 
Unidos”. A partir de 1979, no governo de Figueiredo, algumas relações entre o Brasil e outros países de terceiro mundo foram se consolidando, o que, em certa medida, auxiliou a promover a integração sul-americana consolidada em governos posteriores (CERVO; BUENO, 2002; LAFER, 2018).

Convém acrescentar que, nesse mesmo período, ocorreu a aproximação do Brasil com alguns estados da África que haviam se tornado independentes, tal tendência se acentuava devido ao crescente interesse no continente como um potencial parceiro econômico, comercial, político, cultural e histórico. Esse estabelecimento de relações comerciais e diplomáticas foi fundamentado seguindo o princípio universal em que todos os países seriam potenciais parceiros. Referendou-se, distante, uma das razões para que se adotasse como rótulo da política externa brasileira a qualificação de universalista (PINHEIRO, 2004; MANZUR, 2014).

A partir da década de 80 , alguns objetivos orientaram a política exterior brasileira, tais como: "a) recolocar o Brasil no quadro das relações prioritárias com o Ocidente; b) ampliar o mercado para os produtos de exportação do Brasil." (CERVO, 2004, p.5). Já a partir da constituição do Mercosul por meio da assinatura do Tratado de Assunção, em 1991, favoreceu o processo de ascensão da diplomacia brasileira com países como Argentina, Paraguai e Uruguai que compunham o Mercosul, além de também ter auxiliado na promoção da liderança brasileira nessas regiões (BESHARA; PINHEIRO, 2008).

A intimidade com o Terceiro Mundo criava condições para iniciativas regionais, influía em certas decisões multilaterais e situava o universalismo da diplomacia brasileira na solidariedade (CERVO; BUENO, 2015). Desta maneira, o Brasil buscava legitimar sua posição de liderança na América do Sul, além de consolidar um espaço de atuação internacional independente das orientações dos Estados Unidos (ONUKI, 2006).

Analogamente, as iniciativas educacionais de proporção internacional revelam-se instrumentos e estratégias de política externa, evidenciando, em última análise, as múltiplas dimensões de exercício - portanto de análise - da política externa brasileira (PINHEIRO, 2006). A construção de uma identidade comum para iniciativas educacionais conforme os autores Pinheiro et al. (2007) destacam, exprime um esforço deliberado para aparar diferenças e para criar valores compartilhados, como forma de fomentar a identificação dos países entre si e de esmaecer rivalidades, o que poderia contribuir sensivelmente para o adensamento da integração.

\section{Cooperação Educacional Brasileira}

Os mecanismos de atuação política podem se valer de instrumentos variados. No caso da política externa, por exemplo, as articulações não estão restritas a entendimentos nas esferas comercial, econômica ou militar, mas também se exprimem por meio de acordos centrados em questões culturais e educacionais (BESHARA; PINHEIRO, 2008). Neste 
aspecto, a cooperação educacional figura como um catalisador de políticas, de ordens variadas, que o Brasil possa desenvolver para o bloco; trata-se de um esforço para que sejam reduzidas as rivalidades intra-membros, por meio da formação de valores comuns, de forma a torná-los mais receptivos às investidas brasileiras, aprofundando, assim, a integração (BESHARA, 2007).

De acordo com a Divisão de Temas Educacionais do Itamaraty, os principais objetivos da cooperação educacional brasileira são: a) promover maiores padrões de educação de cidadãos oriundos de outras regiões em desenvolvimento; b) promover diálogo no domínio da educação entre jovens brasileiros e estrangeiros; e c) divulgar a cultura e a língua brasileira (BRASIL, 2020d). A partir desses objetivos, para conceber as ações de cooperação educacional a política externa brasileira age em pelo menos três vertentes, segundo Brasil (2020d): economicamente, a educação, ao relacionar-se diretamente à qualificação da mãode-obra de um país, interfere no desenvolvimento econômico; politicamente, a cooperação educacional representa parte de uma agenda positiva da política externa, ou seja, a visão do Brasil é como um país que age com base em princípios de solidariedade; e a última vertente é a cultural, pois a convivência, o aprendizado do idioma e a troca de experiências contribui para o estreitamento de laços entre as sociedades.

Neste sentido, o Ministério de Educação do Brasil tende a dar prioridade aos programas de intercâmbio com países que apresentam deficiências em seus sistemas de ensino superior, e aos países considerados prioritários nas agendas de política externa brasileira. Desde 2004, as estratégias de cooperação internacional da Coordenação de Aperfeiçoamento de Pessoal de Nível Superior (CAPES) têm enfatizado a América Latina e a África, em particular os Países Africanos de Língua Oficial Portuguesa (PALOP), denominados países lusófonos (MILANI, 2016).

Como decorrência, é necessário que a análise de política externa incorpore o debate sobre essa temática. E mais do que isso, é plausível conceber que, também em suas ações exteriores, os países se valham de medidas educacionais para respaldar suas estratégias e assegurar seus objetivos (PINHEIRO, 2006; PINHEIRO; BESHARA, 2012).

Ainda no tocante à educação, ela pode ser representada como uma das áreas nas quais as políticas públicas nacionais podem se projetar mundialmente, levando soluções brasileiras a problemas enfrentados por diversos países, sobretudo os mais pobres. Convém destacar, contudo, que tais soluções respondem mais a interesses comerciais, ou influências políticoestratégicas do que às reais necessidades de desenvolvimento de países receptores e que muitas vezes essas alternativas são impostas pelos interesses e mecanismos institucionais dos países doadores, sem atentar para as reais necessidades ao desenvolvimento dos países receptores (CANDEAS, 2012).

Diante deste contexto, a educação revela-se como um possível instrumento de promoção de liderança brasileira frente aos países de menor desenvolvimento relativo, devendo-se atentar para os riscos de reprodução de um tipo de experiência - a cooperação topdown, colonizadora, não participativa - entre os países com os quais o Brasil possui acordos de cooperação tanto bilateral quanto multilateral (MILANI, 2012; CERVO; BUENO, 2015). 


\section{Cooperação Sul-Sul}

A cooperação para o desenvolvimento, tal como é conhecida, acontece essencialmente entre os países do Norte com os países do Sul (CNS), surgiu com a Guerra Fria, se institucionalizou e legitimou o multilateralismo da cooperação para o desenvolvimento entre os países desenvolvidos e os subdesenvolvidos de uma maneira horizontalizada (MILANI, 2012).

Nos últimos tempos, foi possível assistir a uma ascensão do chamado "Sul Global” ou "Sul" no cenário internacional, reforçando as relações Sul-Sul, dentre as quais se destaca a cooperação para o desenvolvimento em um mundo ainda altamente desigual (MUÑOZ, 2016). O termo Sul Global é a designação simbólica para denominar uma ampla gama de nações em desenvolvimento, diversificadas em suas histórias, origens e tradições, com múltiplos enfoques no que se refere ao poder, à cultura ou à identidade (SOUZA, 2014).

O conceito de cooperação horizontal ou cooperação Sul-Sul (CSS) adquiriu importância para os países em desenvolvimento em um contexto de descontentamento com as desigualdades entre os países do sistema econômico mundial, em busca do diálogo político e a articulação entre países em desenvolvimento, ou seja, os países do Sul (MILANI, 2012).

Seus antecedentes históricos são a conferência de Bandung, o Movimento dos Nãoalinhados (MNA), o Grupo dos 77 (G-77), primeiros arranjos regionais e subregionais de integração dos anos 1960, a Nova Ordem Econômica Internacional (NOEI) e a Organização dos Países Exportadores de Petróleo (OPEP) (OGWU, 1982). A questão central discutida em Bandung visava conceder os primeiros passos da cooperação política entre países inseridos na periferia do sistema internacional no sentido de deixar de lado suas diferenças em prol de um movimento comum de denúncia das calamidades do colonialismo (MILANI, 2012).

Em despeito da construção do conceito de Cooperação Sul-Sul, a reciprocidade, complementaridade, horizontalidade e solidariedade são premissas inerentes que, nessa perspectiva, se projetam como uma relação de benefícios mútuos entre os países parceiros, pautada, sobretudo, na ausência de condicionalidades, distante de um vínculo assistencialista e seria orientada pela própria demanda dos países parceiros (LEAL; MORAES, 2018; SOUZA, 2014). As premissas deste tipo de cooperação têm o intuito de oferecer aos países maiores oportunidades de aprendizado e aproveitamento das lições aprendidas, uma vez que as condições de vida de suas populações são mais próximas, se comparadas àquelas dos países do Norte.

Entretanto, embora tais países tenham condições econômicas similares, muitos se diferem no que se refere ao seu contexto social, que é heterogêneo não apenas entre os países, como também em seu interior e a parcela de poder de que desfrutam no contexto global. Assim, conforme Santos e Cerqueira (2015) afirmam, a solidariedade presente neste tipo de cooperação não implica em uma completa ausência de diferenças, interesses e conflitos entre os membros do movimento. 
Portanto, os interesses materiais e a assimetria de poder entre os países ainda não estão excluídos das relações Sul-Sul, não sendo possível afirmar, desta maneira, que a cooperação Sul-Sul não possui traços da cooperação Norte-Sul. E, conforme alguns traços da cooperação Norte-Sul, alguns países do Sul estabelecem contrapartidas econômicas na cooperação prestada a outros países com grau de desenvolvimento relativamente inferior (MILANI, 2012).

Estas contrapartidas realizadas por alguns países podem acontecer através da cultura e educação, por serem consideradas importantes fontes de soft power do Brasil internacionalmente, uma vez que contribuem para o reforço dos laços políticos e econômicos entre o Brasil e os países parceiros. Essa é uma ferramenta tradicionalmente empregada pelas potências centrais, tanto quanto por países como China, Índia, México e África do Sul (PINHEIRO; BESHARA, 2012).

A partir da ideia de que projetos políticos de um estado manifestam-se fortemente na constituição de sistemas educacionais nacionais, é possível conceber que, também em suas ações exteriores, os países se valham de medidas educacionais para respaldar suas estratégias e assegurar seus objetivos (PINHEIRO; BESHARA, 2012).

Convém explicar que, mesmo nas relações entre os países do Sul, há uma relação de dependência evidenciada na educação superior mundial contemporânea, e por este motivo, o Brasil deve-se atentar ao fato de procurar não reproduzir práticas com vínculos imperialistas ou neocolonizadoras, de contínua dependência econômica, política, cultural ou educacional (LEAL, MORAES, 2017).

\section{Programa de Estudantes-Convênio de Pós-Graduação Pec-Pg}

A regulamentação do PEC-PG ocorreu em um contexto político econômico em que o Brasil buscava manter o crescimento econômico elevado mesmo após o milagre econômico de 1973, para manutenção desse desenvolvimento, algumas medidas foram estabelecidas, dentre elas, a maior participação brasileira no mercado externo, o desenvolvimento de tecnologias em áreas específicas nas quais o Brasil tinha interesse em se desenvolver e se consolidar mundialmente.

A partir deste objetivo, um conjunto de setores foi considerado prioritário para promoção de exportações. E, conforme Doellinger (1971), as pesquisas agrotécnicas e zootécnicas, começaram a ser consideradas uma alternativa, a fim de que se pudesse desenvolver uma cultura industrializada. Para as empresas nacionais restaria a alternativa da especialização em alguns setores e nestes investir em grande escala, procurando com tal procedimento evitar o esmagamento a que estariam submetidos a maior parte dos setores industriais. Destacavam-se como especializações: 
- Antibióticos, especialmente aqueles baseados em culturas de microrganismos que aqui se desenvolvem em melhores condições naturais (tetracidina);

- Equipamentos agrícolas; equipamentos para indústrias florestais

(madeiras, papel e celulose, etc.), que beneficiariam não só as exportações propriamente ditas como a própria competitividade de nossa indústria florestal, outra potencial exportadora;

- Equipamentos para indústria de alimentos, especialmente no processamento de alimentos tropicais;

- Máquinas e ferramenta;

- Peças e acessórios de veículos.

Outros ramos industriais poderiam ser ainda incluídos, desde que se contasse com indícios de vantagens de custo (DOELLINGER, 1971, p.54).

De acordo com o Circular Postal 7441 de 1982 da criação do PEC-PG estabeleceram-se as primeiras orientações:

Os estudantes devem ter conhecimento adequado do português. Preferência deverá ser dada aos candidatos que tiverem feito ou estejam fazendo curso de português nos CEBs; O interesse do Governo local na formação de profissionais em áreas onde há maior carência de recursos humanos para a execução dos planos de desenvolvimento do país; $\mathrm{O}$ candidato não poderá apresentar candidatura alternativa. A eventual mudança de curso ou transferência de instituição dependerá exclusivamente dos estabelecimentos de ensino (BRASIL, 1982).

A partir da análise dos documentos de consolidação do PEC-PG, de acordo com o Circular Postal 8276 de 1986, cabe destacar que:

[...] só serão aprovados os candidatos que comprovarem possuir condições de manter-se no Brasil, com recursos próprios ou institucionais [...] a partir de 1986, serão ofertadas vagas nos cursos de pós-graduação em Física e Matemática, além das tradicionais vagas de Medicina, Engenharia, Economia e Ciências Agrárias (BRASIL, 1986).

O Programa de Estudantes-Convênio de Pós-Graduação PEC-PG, foi criado oficialmente em 1981 apesar da primeira oferta de vagas ter acontecido em 1983. O PEC-PG oferece bolsas de estudo para estudantes de países em desenvolvimento com os quais o Brasil possui acordo de cooperação cultural, educacional ou científico-tecnológica para formação em cursos de pós-graduação Stricto Sensu (mestrado e doutorado) em Instituições de Ensino Superior (IES) brasileiras (BRASIL, 2020a).

O Programa tem como objetivo, contribuir para a formação de recursos humanos, por meio da concessão de bolsas de mestrado e doutorado para a realização de estudos em IES brasileiras com o intuito de aprimorar a qualificação de professores universitários, pesquisadores, profissionais e graduados do ensino superior, visando sua contribuição para o desenvolvimento dos países. Portanto, o PEC-PG se caracteriza como um programa de cooperação educacional entre países em desenvolvimento (BRASIL, 2020a).

Ao longo da última década o PEC-PG selecionou mais de 3.000 estudantes de pósgraduação. Cerca de $68 \%$ das candidaturas vem de países das Américas, com destaque para Colômbia e Peru. Os países africanos respondem por cerca de $30 \%$ das candidaturas, com destaque para Moçambique e Cabo Verde. Entre os países asiáticos, responsáveis por cerca de

\begin{tabular}{l|l|l|l|l|l}
\hline (C) Rev. Inter. Educ. Sup. & Campinas, SP & v.7 & $1-15$ & e021042 & 2021 \\
\hline
\end{tabular}


$2 \%$ das candidaturas, o Timor-Leste conta com maior número de selecionados. Atualmente, participam do PEC-PG 60 países, sendo 26 na África, 25 nas Américas e 9 na Ásia (BRASIL, 2020b).

Apesar de se tratar de um programa de cooperação entre países em desenvolvimento, tal como preconizam as teorias de Cooperação Sul-Sul, tanto o documento de criação do PEC-PG (1982) quanto o protocolo publicado em 2006 apresentam poucas características de cooperação horizontal com os países em vias de desenvolvimento. $\mathrm{O}$ decreto restringe-se a estabelecer obrigatoriedades, condicionalidades e compromissos bastante rígidos que os estudantes devem atender, a saber:

1) ser cidadão dos países em desenvolvimento com os quais o Brasil mantenha Acordo - de Cooperação Educacional, Cultural ou de Ciência e Tecnologia; 2) não ser portador de visto permanente no Brasil; 3) é vedada a participação de cidadãos brasileiros, ainda que binacionais, assim como de candidatos cujo genitor ou genitora seja brasileiro; 4) ser portador do Certificado de Proficiência em Língua Portuguesa para Estrangeiros (CELPE-Bras), se oriundo de país não lusófono, ou carta do orientador brasileiro pela qual se responsabiliza pela proficiência em português do candidato [...] 7) apresentar duas cartas de recomendação de professores, pesquisadores ou de pessoas de reconhecida competência na área; 8) apresentar currículo em língua portuguesa; 9) apresentar plano de trabalho, em língua portuguesa; 10) apresentar certidão de nascimento ou documento de identidade de seus genitores (BRASIL, 2020c).

Algumas das condicionalidades que os estudantes devem atender são:

1) será dada prioridade aos candidatos que comprovarem ter vínculo empregatício no país de origem. No caso de vínculo com Instituição de Ensino Superior, esses candidatos deverão apresentar a devida comprovação; 2) a documentação relacionada deverá ser apresentada à Missão Diplomática brasileira no país de origem ou de residência fixa do candidato, independentemente de onde ele estiver, inclusive via correio tradicional; 3) todos os formulários anexos [...] deverão ser preenchidos em língua portuguesa; 4) o candidato que tiver concluído o curso superior no Brasil sob o amparo do Programa de Estudantes-Convênio de Graduação (PEC-G) somente poderá participar do PEC-PG caso comprove ter permanecido no país de origem por, pelo menos, dois anos após ter obtido o diploma brasileiro. Casos excepcionais poderão ser acolhidos a critério do Grupo de Supervisão [...] (BRASIL, 2020c).

Alguns dos compromissos que os estudantes devem cumprir: 
Executar o plano de atividades aprovado no âmbito do Programa; Assinar o termo de compromisso obrigando-se a cumprir as metas pactuadas pela IES no projeto e a devolver à agência financiadora eventuais benefícios recebidos indevidamente; Apresentar formalmente os resultados parciais e finais de seu trabalho, por meio de relatórios de atividades anuais, além de pareceres do orientador e histórico escolar, a critério da agência financiadora; Submeter-se às exigências do Programa PEC-PG, inclusive as incluídas no presente manual, às disposições regimentais da IES em que estiver matriculado, e às normas da agência financiadora concessora de sua bolsa; Manter atualizado, junto às autoridades competentes, o visto temporário, sob pena de suspensão temporária da bolsa, com possibilidade de desligamento do programa; Fazer referência ao apoio recebido pela respectiva agência financiadora nos trabalhos publicados em decorrência das atividades desenvolvidas no âmbito do PEC-PG, com as seguintes expressões [...] Se publicado individualmente: "O presente trabalho foi realizado com o apoio do Programa Estudantes-Convênio de Pós-Graduação - PEC-PG, da CAPES/CNPq Brasil". Se publicado em coautoria: "Bolsista do Programa Estudantes-Convênio de Pós-Graduação - PEC-PG, da CAPES/CNPq - Brasil” (BRASIL, 2020c).

O restante dos documentos acerca do PEC-PG não menciona quaisquer indicativos de cooperação ou contrapartidas, pelos quais os países que são responsáveis por encaminhar os estudantes devem cumprir ou desenvolver no Brasil. Os decretos se limitam somente a estabelecer condicionalidades, obrigatoriedades e prerrogativas que todos os estudantes de fora devem cumprir no Brasil, e caso não se façam cumprir algumas das prerrogativas, os estudantes estão sujeitos a sanções junto a Polícia Federal.

\section{Considerações Finais}

O artigo teve o objetivo de verificar em que medida o Programa Estudantes Convênio de Graduação (PEC-PG) pode ser considerado um programa que atende aos princípios da cooperação Sul-Sul. Destaca-se que ao longo de seus mais de 30 anos o PEC-PG se consolidou como uma política de governo cujo intuito principal era o de desenvolver recursos humanos e auxiliar no desenvolvimento de regiões com as quais o Brasil possui acordos por meio da manutenção de pesquisas em instituições brasileiras.

Ao verificar o momento da concepção do PEC-PG, é possível observar que o Brasil estava vivendo um momento após o chamado "milagre econômico" e tanto a economia quanto as empresas precisavam manter o ritmo de crescimento, uma vez que a presença do mercado externo ameaçava o desenvolvimento econômico nacional. Nesse sentido, os documentos de criação do programa, analisados à luz do momento histórico da política externa da época, corroboram com tal compreensão, de que o PEC-PG foi criado sobretudo com vistas à atender demandas econômicas e de promoção do desenvolvimento brasileiro da época e não para auxiliar os países de seu entorno.

Além deste ponto, é possível destacar que o PEC-PG estabelece diversos critérios restritivos, tais como: obrigatoriedade de aprovação em exame de língua portuguesa, não ser portador de visto permanente no Brasil, restrição do tempo de permanência no Brasil após o fim da pós-graduação e a prioridade dada aos alunos que comprovarem ter vínculo 
empregatício no país de origem, ensejando o PEC-PG como um programa muito restritivo e seletivo, devido ao excesso de condicionalidades impostas no regulamento do programa. Tais características parecem afastá-lo do modelo de um modelo de cooperação mútua, porque apesar de oportunizar aos estudantes de diversos países a oportunidade realizar seus estudos em nível de pós-graduação no Brasil não há nenhuma consulta aos países beneficiados sobre as áreas educacionais deficitárias que estão precisando de desenvolvimento.

Torna-se possível afirmar que o PEC-PG se afasta profundamente da narrativa brasileira de Cooperação Sul-Sul (CSS), que prevê que o modelo de colaboração deve contribuir para a construção de uma internacionalização com um viés pautado na cooperação, uma vez que a CSS se lança como relação de benefícios mútuos, pautada na horizontalidade, na ausência de condicionalidades e distante de um vínculo assistencialista (MUÑOZ, 2016).

A partir do exposto com este trabalho, percebe-se a necessidade do desenvolvimento de programas de cooperação mais horizontalizados, reconhecendo-se a necessidade de discussão e aprimoramento de práticas sob a ótica de uma política institucional mais solidária voltada para as necessidades tanto de países beneficiados quanto dos países "doadores" de tais políticas.

\section{Referências}

BESHARA, Gregory; PINHEIRO, Letícia. Educação e política externa: a experiência brasileira no Mercosul Educacional. In: Relatório de Pesquisa "Política Externa e Educação - um estudo comparativo sobre a atuação do Brasil na CPLP e no Setor Educacional do Mercosul”, Instituto de Relações Internacionais da PUC-Rio, 2008. Disponível em: http://www.pucrio.br/pibic/relatorio_resumo2008/relatorios/ccs/iri/iri_gregory_beshara.pdf. Acesso em: 20 março 2020.

BESHARA, Gregory. Identidades Forjadas: o Ensino de História e a Política Externa Brasileira para o Mercosul. In: XV SEMINÁRIO DE INICIAÇÃO CIENTÍFICA DA PUCRIO/CNPQ. Anais. Rio de Janeiro, 2007.

BORTONI-RICARDO, Stella Maris. O professor pesquisador: introdução à pesquisa qualitativa. São Paulo: Parábola Editorial, 2008.

BRASIL. Circular Postal 7441 de 1982. Criação do PEC-PG.

BRASIL. Circular Postal 8276 de 1986. Consolidação do PEC-PG.

BRASIL. Ministério das Relações Exteriores. Programa de Estudantes-Convênio de Graduação. Brasília: Ministério das Relações Exteriores, 2020a. Disponível em: http://www.dce.mre.gov.br/PEC/PECPG.php Acesso em: 20 março 2020.

BRASIL. Ministério das Relações Exteriores. Programa de Estudantes-Convênio de Graduação. Histórico do PEC PG. Brasília: MRE, 2020b. Disponível em: http://www.dce.mre.gov.br/PEC/PG/historico.php Acesso em: 11 março 2020. 
BRASIL. Ministério das Relações Exteriores. Como participar do PEC-PG. Protocolo de cláusulas do PEC-PG (2006). Brasília: MRE, 2020c. Disponível em:

http://www.dce.mre.gov.br/PEC/PG/Protocolo_PECPG.pdf Acesso em: 10 março 2020.

BRASIL. Ministério das Relações Exteriores, Diplomacia Cultural. Brasília: MRE, 2020d.

Disponível em:

http://www.itamaraty.gov.br/index.php?option=com_content\&view=article\&id=698\&Itemid $=215 \&$ lang=pt-BR Acesso em: 10 março 2020 .

BURRELL, G.; MORGAN, G. Sociological paradigms and organizational analysis. London: Heinemann Educational Books, 1979.

CANDEAS, Alessandro Educação e política externa: a experiência brasileira no Mercosul Educacional. In: Pinheiro, L.\& Milani, C. R. S. (Org.). Política externa brasileira a política das práticas e as práticas da política. Rio de Janeiro: FGV, 2012.

CERVO, Amado Luiz; BUENO, Clodoaldo. História da Política Exterior do Brasil. Brasília: Instituto Brasileiro de Relações Internacionais/Editora da Universidade de Brasília, 2002.

CERVO, Amado Luiz. Política exterior e relações internacionais do Brasil: enfoque paradigmático. Revista Brasileira de Política Internacional, Brasília, DF, v. 46, n. 2, p. 525, jul./dez, 2003.

CERVO, Amado Luiz; BUENO, Clodoaldo. História da Política Exterior do Brasil. Brasília: Editora da Universidade de Brasília, 2015, 605 p.

DENZIN, Norman K; LINCOLN, Yvonna (Org). Planejamento da pesquisa qualitativa: teorias e abordagens. 2 ed. Porto Alegre: ARTMED, 2006.

DOELLINGER, C. Exportações brasileiras: diagnóstico e perspectivas. Revista Brasileira De Economia, 26(1), 51-104, 1972. Disponível em:

http://bibliotecadigital.fgv.br/ojs/index.php/rbe/article/view/71 Acesso em: 20 março 2020.

LAFER, Celso. Relações internacionais, política externa e diplomacia brasileira: pensamento e ação. FUNAG, 2018.

LEAL, Fernanda Geremias; MORAES, Mário César Barreto. Política Externa Brasileira, Cooperação Sul-Sul e Educação Superior: o Caso do Programa Estudante-Convênio de Graduação. Educ. Soc., v.39 n.143, 343-359, 2018.

MANZUR, Tânia Maria P. G. A política externa independente (PEI): antecedentes, apogeu e declínio. Lua Nova: Revista de Cultura e Política, (93), 169-199, 2014.

MILANI, Carlos R. S. Aprendendo com a história: críticas à experiência da Cooperação Norte-Sul e atuais desafios à Cooperação Sul-Sul. Cad. CRH, 2012, vol.25, no.65, p.211$231,2012$.

MILANI, C.R.S. et al. Atlas da política externa brasileira. Rio de Janeiro: Editora da UERJ, 2015.

\begin{tabular}{l|l|l|l|l|l|}
\hline (C) Rev. Inter. Educ. Sup. & Campinas, SP & v.7 & $1-15$ & $\mathrm{e} 021042$ & 2021 \\
\hline
\end{tabular}


MILANI, Carlos R. S.; CONCEICAO, Francisco Carlos; M'BUNDE, Timóteo Saba. Cooperação Sul-Sul Em Educação E Relações Brasil-Palop. Cad. CRH, Salvador, v. 29, n. 76, p. 13-32, 2016.

MOROSINI, Marília Costa. Internacionalização na produção de conhecimento em IES Brasileiras: cooperação internacional tradicional e cooperação internacional horizontal. Educação em Revista, v. 27(1), p. 93-112, 2011. Disponível em: http://www.scielo.br/scielo.php?script=sci_arttext\&pid=S0102$46982011000100005 \& \operatorname{lng}=\mathrm{en} \& n r m=i s o$. Acesso em março de 2020.

MUÑOZ, Enara Echart. A Cooperação Sul-Sul Do Brasil Com A África. Cad. CRH, Salvador, v. 29, n. 76, p. 9-12, 2016.

OGWU, J.U.A. La cooperación Sur-Sur: problemas, posibilidades y perspectivas en uma relación emergente. Nueva Sociedad, n. 60, p. 557-558, 1982.

ONUKI, Janina. O Brasil e a Construção do Mercosul. In: ALTEMANI, H.; LESSA, A.C. (Org.) Relações Internacionais do Brasil: temas e agendas. Vol. 1, São Paulo: Saraiva, 2006.

PINHEIRO, Letícia. Política externa brasileira (1889 - 2002). Rio de Janeiro: Jorge Zahar Editores, 2004.

PINHEIRO, Letícia. (coordenação) Projeto "Expansão, Renovação e Fragmentação das Agendas e dos Atores de Política Externa" / Programa Renato Archer de Apoio à Pesquisa em Relações Internacionais. Apoio CNPq. 2006

PINHEIRO, Letícia. Educação, Identidade e Política Externa - debate acadêmico e possibilidades empíricas. In: $1^{\circ}$ ENCONTRO NACIONAL DA ASSOCIAÇÃO BRASILEIRA DE RELAÇÕES INTERNACIONAIS. Anais. Brasília, DF, julho 2007.

PINHEIRO, Letícia. BESHARA, Gregory. Política externa e educação: confluências e perspectivas no marco da integração regional. In: PINHEIRO, L.; MILANI, C. R. S. (Org.). Política externa brasileira: as práticas da política e a política das práticas. Rio de Janeiro: FGV, 2012. p. 149-180.

SANTOS, R. De Freitas; CERQUEIRA, Mateus R. Cooperação Sul-Sul: experiências brasileiras na América do Sul e na África. História, Ciências, Saúde - Manguinhos, Rio de Janeiro, v.22, n.1, p.23-47, 2015.

SCHUTZ, A. Fenomenologia e relações sociais: textos escolhidos. Rio de Janeiro: Zahar, 1979.

SOUZA, A.M. Repensando a cooperação internacional para o desenvolvimento. Brasília: IPEA, 2014.

ZAKARIA, Fareed. The Post-American World. W. W. Norton \& Company. United States, 2008. 